\title{
PREVALENCE OF ABSENCE OF PALMARIS LONGUS TENDON IN NEPALESE POPULATION
}

\author{
Nitasha Sharma, ${ }^{1}$ Bikash Parajuli, ${ }^{2}$ Niraj Pandey, ${ }^{1}$ Ram Prakash Shah ${ }^{1}$
}

\section{ABSTRACT}

\section{INTRODUCTION}

The palmaris longus (PL) is a tendinous superficial flexor of forearm. It basically, anchor skin and fascia of hand resist the horizontal shear force in distal direction. It also helps in tightening of palmar aponeurosis. Along with other flexor muscle it also helps in flexion of wrist joint. The incidence of absence of palmaris longus is in great variation from 1.5 to $63.9 \%$. Its variation of absence has attracted many researchers globally. The aim of the present study is to know occurrence of absence of PLin Nepalese population.

\section{MATERIAL AND METHODS}

This is a cross sectional descriptive observational study conducted among 270 medical students (MBBS, BDS) at Universal College of Medical Science, Bhairawaha in year the 2018-2019. Ethical approval for study was taken from institutional review committee (IRC). Four tests-Schaeffer's Test, Thompson's Fist, Mishra's Test and Puspa Kumar's two finger sign were used to see the absence/presence of Palmaris longus. A semi-structured proforma was used to collect the data.

\section{RESULTS}

Out of 270 students, there were 145 (53.7\%) females and 125 (46.3\%) males. Age of the subject range from 19-23 years with a mean age of 19.91 years. The overall absence of palmaris longus was seen in 40 students $(14.8 \%)$ which included 18 males (14.4\%) and 22 females (15.2\%). Bilateral absence of palmaris longus was seen in 10 students (3.7\%) whereas unilateral absence of palmaris longus was seen 14 males $(11.2 \%)$ and 16 females $(11.03 \%)$.

\section{CONCLUSION}

This present study concluded that overall absence of palmaris longus was seen in $14.8 \%$ subjects. Gender wise distribution showed that $14.4 \%$ males and $15.2 \%$ had the absence of palmaris longus. Thus, sound knowledge about this variation is important in planning graft surgeries.

KEY WORDS Palmaris longus, flexor, forearm

1. Department of Anatomy, UCMS, Bhairahawa, Nepal

2. Kathmandu University, Dhulikhel Hospital, Kavre, Nepal

DOI: https://doi.org/10.3126/jucms.v7i1.24683

\author{
For Correspondence \\ Dr. Nitasha Sharma \\ Department of Anatomy \\ Universal College of Medical Sciences \\ Bhairahawa, Nepal \\ E-mail:sharmanitasha8868@gmail.com
}




\section{INTRODUCTION}

The palmaris longus (PL) is a, tendinous superficial flexor of forearm. ${ }^{1}$ Superficial muscles of forearm includes flexor carpi ulnaris, palmaris longus, flexor carpi radialis and pronator teres. Palmaris longus is a thin spindle shape long slender tendinious muscle between flexor carpi ulnaris and flexor carpi radialis. ${ }^{2-6} \mathrm{PL}$ originated from medial epicondyle of and epicondyle ridge of humerus with common flexor tendon. ${ }^{3} \mathrm{PL}$ further runs downwards as a long slender tendon passing anterior through the transverse carpal ligament and insert into flexor retinaculum and palmar aponeurosis. ${ }^{7.8}$ Its nerve supply is by median nerve and arterial supply is by ulnar artery. ${ }^{1,3}$

Palmaris longus basically, anchor skin and fascia of hand resist the horizontal shear force in distal direction. It also helps in tightening of palmar aponeurosis. Along with other flexor muscle it also helps in flexion of wrist joint.

The knowledge of PL is a growing interest for its wide role in reconstructive plastic surgery orthopedics as well urosurgery as transfer or transplant graft ${ }^{5}$, lip augmentation or escalation ${ }^{6}$ ,ptosis correction ${ }^{7}$, management of facial paralysis ${ }^{8}$ and urinary incontinence. ${ }^{4}$

The incidence of absence of palmaris longus is in great variation ${ }^{9}$ from 1.5 ( Korean) to $63.9 \%$ (Turkish) population. ${ }^{10}$ Its variation of absence has attracted many researchers globally. However, most of the studies have been done in Caucasian populations. ${ }^{11}$ The aim of the present study is to know occurrence of absence of PL, clinically in Nepalese population and to compare the result of this study globally which will help surgeons and orthopedicians in our regions. ${ }^{12,13}$

\section{MATERIAL AND METHODS}

A cross sectional descriptive observational study was conducted among 270 medical students (MBBS, BDS) at Universal College of Medical Science, Bhairawaha which include 145 male and 127 female in year the 2018-2019. Exclusion criteria were students not willing to participate in the study.

Ethical approval for study was taken from institutional review committee (IRC) of Universal College of Medical Science vide their letter no. ucms/irc/189/18 dated $8^{\text {th }}$ Dec 2018. In the study, the prevalence of presence and absence was determine by series of tendon examination test.

1. Schaeffer's Test: ${ }^{14}$ Student is asked to hold forearm at 90 degree, than to oppose the thumb with little finger and wrist is flexed (Fig 1-a).

2. Thompson's Fist: ${ }^{15}$ Student is made to close the fist, with thumb above other finger and wrist is flexed agains ${ }^{t}$ resistance (Fig 1-b).

3. Mishra's Test: ${ }^{16}$ Student is made to do passive hyperextension of metacarpophalangeal joint with active wrist flexion (Fig 1-c).

4. Puspakumar's two finger sign: ${ }^{17}$ Student are made to extend $2^{\text {nd }}$ and $3^{\text {rd }}$ digits, flex $4^{\text {th }}$ and fifth digit with first digit fully opposed and flexed(Fig 1-d).

If PL is not visible in all test, it will be taken as absent in that subject.
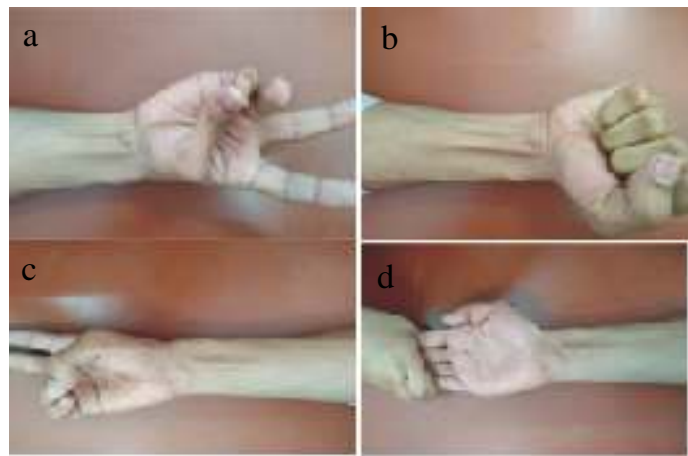

Figure 1 (a-d). Showing different clinical tests done for palmaris longus

The data were entered in excel worksheet and analysed in SPSS versio2.0.Chi-Square test was used .P-value less than 0.05 was considered statistically insignificant.

\section{RESULTS}

Out of 270 students, there were 145 (53.7\%) females and 125 (46.3\%) males. Age of the subject range from 19-23 years with a mean age of 19.91 years. The overall absence of palmaris longus was seen in 40 students (14.8\%) which included 18 males (14.4\%) and 22 females (15.2\%) (Fig. 2).

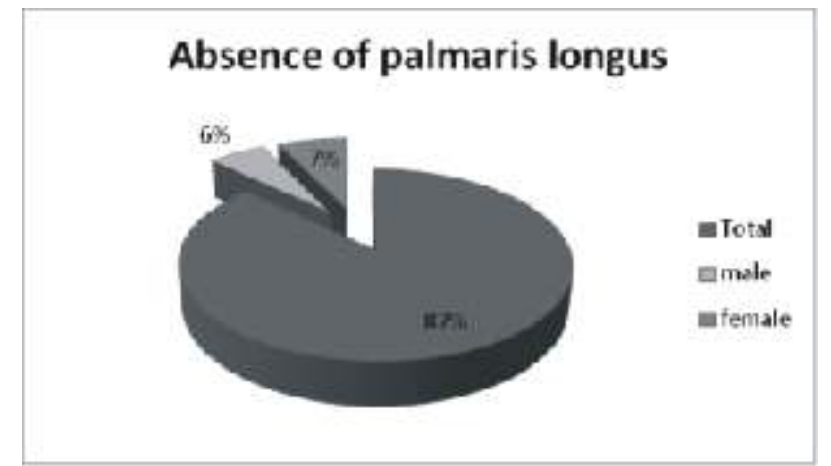

Figure 2. Pie chart showing overall absence of palmarislongus 
Out of 270 students, Bilateral absence of palmaris longus was seen in 10 students $(3.7 \%)$ whereas unilateral absence of palmaris longus was seen 14 males $(11.2 \%)$ and 16 females $(11.03 \%)$.

Out of 125 male students $18(14.4 \%)$ students had absence of palmaris longus, $9(7.2 \%)$ students had absence of palmaris longus in left hand and $5(4 \%)$ students had absence of palmaris longu in left hand. Bilateral absence of palmaris longus was seen in $4(3.2 \%)$ males.

Among 145 female students 22 (15.2\%) students had overall absence of palmaris longus where $9(6.2 \%)$ students had absence of PL on left hand and 7 (4.8\%) students had absence of PL on right hand. Bilateral absence of PL was seen in $4.1 \%$ females.

Table 1. Showing frequency of absence of PL by its lateralization

\begin{tabular}{lllll}
\hline & $\begin{array}{l}\text { Absent of PL in } \\
\text { Right Side }\end{array}$ & $\begin{array}{l}\text { Absent of PL in } \\
\text { Left Side }\end{array}$ & $\begin{array}{l}\text { Absent of PL } \\
\text { Bilaterally }\end{array}$ & \\
\hline Male $(\mathrm{n}=125)$ & $5(4 \%)$ & $9(7.2 \%)$ & $4(3.2 \%)$ & $18(14.4 \%)$ \\
Female $(\mathrm{n}=145)$ & $7(4.8 \%)$ & $9(6.2 \%)$ & $6(4.1 \%)$ & $22(15.2 \%)$ \\
\hline Total $(\mathrm{n}=270)$ & $12(4.4 \%)$ & $18(6.7)$ & $10(3.7 \%)$ & $40(14.8 \%)$ \\
\hline
\end{tabular}

Table 2. Showing frequency of absence by gender distribution

\begin{tabular}{lllllll}
\hline Gender & No agenesis & Agenesis & $\begin{array}{l}\text { Unilateral } \\
\text { Agenesis }\end{array}$ & $\begin{array}{l}\text { Bilateral } \\
\text { Agenesis }\end{array}$ & $\begin{array}{l}\text { Left side } \\
\text { agenesis }\end{array}$ & $\begin{array}{l}\text { Right } \\
\text { side } \\
\text { agenesis }\end{array}$ \\
\hline Male (125) & $\begin{array}{l}107 \\
(85.6 \%)\end{array}$ & $18(14.4 \%)$ & $14(11.2 \%)$ & $4(3.2 \%)$ & $9(7.2 \%)$ & $5(4 \%)$ \\
$\begin{array}{l}\text { Female } \\
(145)\end{array}$ & $\begin{array}{l}123 \\
(84.8 \%)\end{array}$ & $22(15.2)$ & $16(11 \%)$ & $6(4.1 \%)$ & $9(6.2 \%)$ & $7(4.8 \%)$ \\
\hline $\begin{array}{l}\text { Total } \\
(\mathrm{n}=270)\end{array}$ & $\begin{array}{l}230 \\
(85.2 \%)\end{array}$ & $40(14.8 \%)$ & $30(11.1 \%)$ & $10(3.7 \%)$ & $18(6.7 \%)$ & $\begin{array}{l}12 \\
(4.4 \%)\end{array}$ \\
\hline
\end{tabular}

\section{DISCUSSION}

Palmaris longus is often described as one of the most variable muscles in the human body and is classified as a phylogenetically retrogressive muscle i.e a short belly with a long tendon. ${ }^{18}$

The palmaris longus tendon is often considered the ideal donor for tendon grafts for replacement of the long flexors of the fingers, and of the flexor pollicis longus tendon. ${ }^{19}$

The palmaris longus muscle is well developed in the animal species, which tolerates more weight on the upper limbs than other species. But in the human species, in which the role of the upper limbs in toleration of body weight has been decreased, the palmaris longus muscle is less developed and uncompleted. ${ }^{20}$

Absence of the palmaris longus muscle has been the subject of studies performed by many researchers in living and deceased people, and the occurrence percentage was variable in different populations and races.

Various clinical anatomy textbooks report around 15\% absence of palmaris longus muscles. ${ }^{21}$ However, this figure differs in various regions of the world. ${ }^{13}$

The overall prevalence of absence of palmaris longus our study was found to be $14.8 \%$ subjects which is similar to the findings by Ali et $\mathrm{al}^{10}$, Berhe $\mathrm{T}$ et $\mathrm{al}^{22}$ Bilateral agenesis was seen in $3.7 \%$ cases consistent with the finding by Jha R et al. ${ }^{12}$

It was found that the overall absence of PL was more common in females $(15.2 \%)$ as compared to males $(14.4 \%)$ which was in accordance with the findings by Lamichhane PS et al. ${ }^{23}$

Unilateral absence of PL was almost equally prevalent in both the sexes. Absence in the Left side was more common in males (7.2\%) whereas right side absence was slightly more common in females $(4.4 \%)$. This finding may be due to the fact that the dominant hand is more involved in manual activities and therefore it is less likely to degenerate due to disuse as compare to the non dominant hand.

The only limitation of this study was that the presence of a palmaris longus muscle was determined by clinical exam, which can be examiner dependent, rather than ca-daveric dissection. To minimize this issue, four different tests were used to detect the palmaris longus muscle.

\section{CONCLUSION}

This present study concluded that overall absence of palmaris longus was seen in $14.8 \%$ subjects. Gender wise distribution showed that $14.4 \%$ males and $15.2 \%$ had the absence of Palmaris longus. Thus, sound knowledge about this variation is important in planning for graft surgeries.

\section{REFRENCES}

1. Standring S. Pectoral girdle and upper limb. Gray's anatomy. $39^{\text {th }}$ ed.London:Elsevier Churchill Livingstone(2005).p.877-78.

2. Ebrahim N, Mohsen P, Hassan M. The Prevalence of Absence of the Palmaris Longus Muscle Tendon in the North of Iran: A Comparative Study.Iran Red Cresent Med J.2016 mar;18(3).

3. Sebastin SJ, Puhaindran ME, Lim AY, Lim IJ, Bee WH. The prevalence of absence of the palmaris longus-a study in a Chinese population and a review of the literature. Journal of Hand Surgery. 2005 Oct;30(5):525-7.

4. K.devi Sankar, P. Sharmila Bhanu, S John. Indian Journal of Plastic surgery .Jan-Apr 2011 vol 44 issue 1. 
5. Davidson BA. Lip agumentation using the palmaris longus tendon. PlastReconstrSurg 1995;51108-10.

6. Naugle TC Jr,Faust DC. Autogenous palmaris longus tendon as frontalis suspension material for ptosis correction in children. Am J Opthal 1999; 127:488.

7. Wehbé MA. Tendon graft donor sites. J Hand Surg Am. 1992;17: 1130-2.

8. Torah F,BaibakGJ, Kelleher JC. Frequency of the palmaris longus tendon in North American Caucasians. AnnPlastsurg 1990;25:477-8.

9. Ioannis Dimitriou, Anastasios Katsourakis, Konstantinos Natsis,Lazaros Kostretzis, Georgios Noussios. Palmaris Longus Muscle's Prevalence in Different Nations and Interesting Anatomical Variations: Review of the Literature. JClinic Med Res.2015 Nov; 7(11):823-30.

10. Ali M. Soltani, MirnaPeric, Cameron S. Francis, Thien-Trang J. Nguyen, Linda S. Chan. The Variaton in the Absence of Palmaris longus in a Multiethnic Population of the united States: AnEpidemiological Study. Plastic Surgey International.vol 2012.doi:10:1155/2012/282959.

11. Agarwal P. Absence of the Palmaris Longus tendon In Indian Population. Indian Journal of Orthopaedics 2010;44(2):212215.

12. Ranjib Jha,Yogendra gupta, and Rimu Mishra,"Absence of Palmaris Longus. A Study in Eastern Nepal.. .American journal of Public Health Research,2015;3(5):88-90.doi: 10.12691 /ajphr-3-5A-18.

13. Dilip K. Mehta, Rajeev Shrestha Dil I. Mansur, , Shobha Shah, Retina Shrestha and Binod Timilsina. Prevalance of the absence of Palmaris Longus Muscle in the students of Kathmandu University. Indternational journal of Biomedical Research. $2015 ; 6$ (12):953-957.

14. Schaeffer JP. On the variations of the Palmaris longus muscle. Anatomy Record 1909; 3: 275-278.

15. Thompson JW, McBatts J, Danforth CH. Hereditary and racial variations in the musculus Palmaris longus. American Journal of Physical Anthropology 1921; 4: 205-220.

16. Mishra S. Alternative tests in demonstrating the presence of Palmaris longus. Indian Journal of Plastic Surgery 2001; 34(2): 12.

17. Pushpa kumar SB, Hanson RP, Carroll S. The 'two finger' sign. Clinical examination of Palmaris longus (PL) tendon. British Journal of Plastic Surgery 2004; 57(2): 184-185.

18. Koo C C, Roberts A H N. The palmaris longus tendon. another variation in its anatomy. J Hand Surg 1997;22-B: 138-9.

19. Zeybek A, Gurunluoglu R, Cavdar S, Bayramiqli M. A clinical reminder: a palmaris longus muscle variation. Ann Plast Surg 1998; 41:224-5.
20. Reimann AF, Daseler EH, Anson BJ, Beaton LE. The palmaris longus muscle and tendon; a study of 1600 extremities. Anat Rec.1944;89:495-505.

21. Standring S. Gray's anatomy, 40th edn. Elsevier Churchill Livingstone, Edinburg, 2008.

22. Berhe T, Bekele A. Agenesis of palmaris longus muscle among selected Ethiopian students. Anat Physiol. 2014;4(136):21610940 .

23. Lamichhane P, Sharma K, Lamichhane N. Study on Palmaris Longus Muscle Tendon Agenesis Among First Year Filipino Medical Students. JGMCN . 1Aug.2017;10(1):17-20. 